\title{
Actors and Networks or Agents and Structures: Towards a Realist View of Information Systems
}

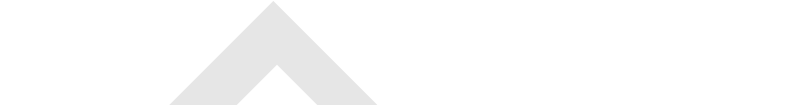

Abstract

Actor-network theory (ANT) has achieved a measure of popularity in the analysis of information systems. This paper looks at ANT from the perspective of the social realism of Margaret Archer. It argues that the main issue with ANT from a realist perspective is its adoption of a 'flat' ontology, particularly with regard to human beings. It explores the value of incorporating concepts from ANT into a social realist approach, but argues that the latter offers a more productive way of approaching information systems.
\end{abstract}

"In matters of grave importance, style, not sincerity, is the vital thing." - Gwendolen, in The Importance of Being Earnest (Wilde, 1986: 301)

\section{Introduction}

This is written from the marcherlands, the debatable territory between information systems and organisational studies. Actually, that might be to stretch the historical analogy a little too far. For the border lands between England and its neighbours Wales and Scotland were characterised for much of the period up to the seventeenth century by incessant feuding. In our debatable territory, by contrast, 
the opposing hordes tend to march straight past each other and not lock horns directly. A pertinent example for the discussion which follows is contained in the treatments of the impact of information technology (IT) in the British National Health Service. Both Bloomfield (1995) and Checkland and Holwell (1998) have a focus on the initiative known as Resource Management, but neither refers to the other. Given the increased importance of topics such as knowledge management and the clear relationship of this to information systems and technology on the one hand, and to organisational structures and actors on the other, such a situation seems less than helpful. This article is concerned with the contribution that social theory can make to our analysis of information systems within organisations.

The relatively under-developed nature of theoretical approaches in the IS domain is frequently bemoaned, with writers such as Checkland and Holwell (1998: xii) calling for acts of 'conceptual cleansing'. However, they are clearly sceptical about the value of existing discussions in the organisational domain, choosing to ignore work they find there. Their reason for this is that "Many academics, even including some in management schools, never move beyond the disputes over ideas and theory construction, being interested in the arguments for their own sake" (Checkland and Holwell, 1998: xiv). Their approach is firmly bedded in an interventionist orientation to real world problems, seeking to derive conceptual positions from such interventions. As such, their approach mirrors that of the persistent calls for 'relevance' found within the IS discourse. (See, for example, several contributions to the recent collection in Currie and Galliers (1999)). This call for relevance has two implications. One is that it tends to have a fairly simplistic approach to organisational issues, which are often illuminatingly referred to as 'behavioural' in character. The second is for the demands 
of systems development to have a considerable weight, demands which bring with them the language of 'hard' systems.

Of course, for many in the organisational domain, systems thinking is irretrievably entangled with a structural-functionalist perspective. The appeal here is towards a 'processual-relational' form of analysis (Watson and Harris, 1999), particularly in the growing area of knowledge. Here there seems to almost an impatience with mundane questions of data and information, still less with technology. The consequence seems to be an ignoring of the content of technology. Baumard (1999), for example, in his discussion of the way in which an Executive Information System in the Australian airline Quantas failed to meet the needs of 'communities of practice’, not only ignores any other literature on such systems but also writes of it as a 'Knowledge Management System' in a way which would no doubt delight the hearts of the rebadging departments of software makers. This sense of technology as infinitely malleable leads to a failure to recognise the specificities of particular applications and the constraints which they might impose. For Grint and Woolgar (1997), such talk of constraints is a lingering commitment to a residual 'technism' which needs to be excised from our analysis. That is, we need to place our emphasis on the interpretations of technology rather than supposing that it has any particular characteristics, sui generis. They pursue this agenda not only against the proponents of the applicability of structuration theory to information systems, but also against advocates of actornetwork theory (ANT). As we shall see, the two have been applied either separately or together to this domain. Indeed, Monteiro and Hanseath (1996) call ANT in to correct the deficiencies (as they see them) of structuration theory, whilst still holding to the value of the latter. This paper therefore needs to suggest both what might be taken from ANT as well as why Archer's morphogenetic approach 
offers more than structuration theory. In doing so, it holds to the notion that technology has emergent properties that can be realised in particular contexts and that our analysis of such contexts needs to focus on the inter-relationship between organisational forms and technologies. Ideas drawn from ANT, such as inscription and irreversibility are helpful here, but Archer's social realism provides a stronger framework than that offered by structuration theory.

A recent collection of case studies of information systems strategy formation uses ANT as its dominant organising theme, arguing that it has 'recently been imported into the information-systems field as an interesting way to understand the influences and the 'actions' performed by technology (Ciborra et al, 2000: 7). This paper looks at some of the implications of ANT from the standpoint of a tradition often seen as diametrically opposed to it, that of the social realism of Margaret Archer (1995, 1996) which has its roots in the development of critical realism by Roy Bhaskar (Collier, 1994). My central argument would be that this work offers valuable help to those who wish to analyse IS in organisations, but that it needs further development. In the rest of this introduction I outline some key facets of this approach, followed by some comments on what constitutes ANT. I then examine some important tensions between social realism and ANT, to see if insights from the latter can inform a development of the form. This then leads to some thoughts on how some of the notions developed in ANT, with appropriate qualifications, might contribute to a realist approach.

I would want, at this early point, to be self-reflexive, in good post-modern style, about issues of style. Something of my prejudices in this area might be gleaned from the use of an Oscar Wilde quotation at the head of this paper. Bruno Latour (1987) himself draws attention to the enormous range 
of allies enrolled in scientific papers, by means of citations. We face not the individual scientist but a whole army of them, armed with instruments, laboratories and other devices. Far worse, however, when we face the theorists of actor-networks, for we are also faced with the question of style. Even those critical of the work done in the broad area of the social study of scientific knowledge (SSK) admire it for its wit (Rose, 1993). Rejecting the concealed rhetoric of the purported objectivity of the scientific paper, adherents revel in allusion, comparison, analogy and sheer wit. This leaves the critic feeling somewhat disarmed before the task of critique begins. How much better to follow suit, how much safer to avoid the charge of being boring (being one "who rehearse[s] with increasing monotony stories about the state, late capitalism, and the labour process” (Miller, 1997:363)), how much more exciting to mix the voices and blur the boundaries? And yet, and yet ... Perhaps this is an issue of intellectual socialisation, but the more austere tracing of logical relationships that marks, in particular, the work of Margaret Archer seems to me both more satisfying and more convincing. By this, I am referring to the frameworks that Archer proposes that should be applied to analysis. There is nothing 'logical' in the sense of inevitability in the concrete social situations that are to be analysed. However, Archer suggests that we need to be clearer about, for example the connections between ideational change and social change, arguing that, for example, change in the former can happen without there being any necessary connection with or impact on social interaction. These ideas are explored in considerable detail in Culture and Agency (1996) and represent an ambitious attempt to suggest relationships that might be explored (Willmott, 2000). The scale of such explorations in Archer's work is such that it can seem daunting to apply these ideas to the mundane functioning of organisations, a point I return to later. I confess, however, (and you can take this as sincere or rhetorical as you wish) that trying to follow the trails, to uncover what I would call the rational kernel in ANT and its 
associated literature is for me a daunting task. It assumes a familiarity with bodies of literature and ideas that are formidable in their range and scope. Whilst this paper can only, by its nature, focus on a few of these areas, I hope to pick those which might have some significance.

One of the problems with social theory, as seen from the perspective of IS research, is its broadbrush approach to information and technology. Giddens, for example, has much on the impacts of technology in late modernity, with its compression of time and space. However, as Jones (1999) has argued, despite its popularity with IS researchers, structuration theory actually allows little purchase on technology. Given, Jones argues, the emphasis on structures as memory traces, instantiated only in action, there seems little place for technology as reflecting, perhaps, more enduring patterns. It is this temporal dimension that Montiero and Hanseath find to be missing in their critique of the application of structuration theory to information systems. Whilst accounts (Walsham, 1993; Orlikowski, DeSanctis and Poole, 1994) place an emphasis on the duality of technology, that is, the way in which technology both enables or constrains human action, whilst at the same time being changed by that action, they fail, on Monteiro and Hanseath's account, to be specific enough about the technology. It is this specificity about the nature of technology and the unfolding process that shapes it that they find helpful in ANT. However, they continue to reserve a place for structuration theory in dealing with the institutional context. However, we will part company with Giddens at this point, as Archer's account is centred on a trenchant critique of what she calls his 'central conflationism'.

Structuration theory had for a time some influence on critical realism as it emerged from a concentration on science to deploy its tools on social life in the work of Bhaskar. However, this flirtation with Giddens receives short shrift in the work of Margaret Archer, whose social realism is 
the most fully developed application of notions drawn from realism to social life. Archer (1995) argues that accounts of social life have tended either to 'downward conflationism' (e.g. variants of structuralism), in which social action is seen as an epiphenomenon of deeper structural conditioning, or 'upward conflationism' (e.g. Symbolic Interactionism) in which persistent structures are downplayed (or ignored) in favour of an explication of the processes of social interaction. Giddens' attempts to overcome these twin poles by emphasising the mutual constitution of agency and structure, she argues, fails to recognise the need to examine the inter-relationships between the two. In practice they can be seen, in the words of Callinicos (1985), to resolve the tension at the pole of agency. Her work not only develops this critique but also an alternative approach, the morphogenetic approach which we review in greater detail below. Even here, however, we have little on technology itself, save a critique of information age theorists (Archer, 1990). What we perhaps sense is an over-riding fear of the charge of technical determinism leading such writers away from any consideration of the role which technology might play in social life (Grint and Woolgar, 1997).

This could, of course, account for the welcome given by some IS researchers to the tenets of ANT, an approach which takes technology very seriously. The problem for a review of this nature is the specification of just what ANT is. Whilst most closely associated with the work of Bruno Latour, it has attracted a variety of followers and interpretations, leading Latour to memorably declare that there are four things wrong with ANT - the words 'actor', 'network' and 'theory' and the hyphen! (Latour, 1999) In what follows, I shall draw principally on Latour, but also on other sources, notably the overview provided by Walsham (1997) and the applications to IS by Bloomfield (1995) and Monteiro and Hanseath (1996). Latour has often been seen as falling into the post-modern camp, most scathingly 
by Sokal and Bricmont (1998). However, Latour himself reserves some of his harshest words for postmodernism ("I have not found words ugly enough to designate this intellectual movement - or rather, this intellectual immobility through which humans and non-humans are left to drift” (1993: 61)) and Christopher Norris (1998), much of whose work is complementary and complimentary to that of Bhaskar, argues that Sokal and Bricmont are rather too hasty in their dismissal of him. Whilst, therefore, the two traditions, as we will see below, have tended to talk past each other, there does seem to be some value in a serious consideration of the work from a realist perspective. In what follows, therefore, I sketch out what seem to me to be some key areas of debate and difference.

\section{Key areas}

Both social realism and ANT share a common origin in concerns about the nature of science. However, they have taken different approaches to this which have seen their development and later extension into the social domain occur in parallel. Bhasksar's work on science started from a dissatisfaction with the outcome of the critiques of both Popper and Kuhn (Collier, 1994; Outhwaite, 1987). Bhaskar started from the naturalistic perspective of asking that, given that science seemed to produce results that we could live by, what did this imply about the world? What it implied, he argued, was the existence of a reality beyond our knowing of it which meant that scientists in practice did not, a la Popper, seek to falsify through the creation and observation of concrete tests. Rather, by the nature of reality, they were concerned to explore the causal mechanisms which operated to produce what might seem real at a superficial level. This endeavour, then, was in the philosophy of science and was concerned primarily with ontology, that is with what is. Latour's work, by contrast, has primarily been 
founded in an anthropological approach which is concerned with questions of epistemology, that is, with how we know what is. He has been concerned to 'follow scientists around' and to construct rules which can help in this process. In doing so, both fields have developed in almost mutual ignorance (or worse) of each other's work. Latour, for example, has a scathing reference to Bhaskar in the 1979 account of Laboratory Life, (Latour and Woolgar, 1979) but to my knowledge, nothing since. Certainly his work seems to take not to take account of not only Bhaskar's project but also the (often closely related) work of feminist scholars of science such as Hilary Rose (1993) or the thoughts of practising scientists such as Steven Rose (1993). At least these latter take account of Latour's existence, if only to criticise it, criticisms which we will explore in what follows. However, the failure of minds to meet can be seen in Sokal's comments on Latour's 'Third Rule of Method'. In this, he argues that

Since the settlement of a controversy is the cause of Nature's representation, not the consequence, we can never use the outcome -- Nature -- to explain how and why a controversy has been settled. (Latour, 1987: 99)

Sokal criticises this on the grounds that it confuses the representation of Nature with Nature itself, although he does argue that this could be seen as more of a methodological point. However, Latour himself makes it clear that this rule only applies when 'following scientists around'. That is, he accepts, albeit grudgingly, that there are aspects of science which can be taken as real. ('There are substances', he accepts, ‘that have been there all along' (Latour, 1999: 170) but the point is how they have interacted with humans to modify the characteristics of each other. As he suggests 'If we try to 
comprehend techniques whilst assuming that the psychological capacity of humans is forever fixed, we will not succeed in understanding how techniques are created nor even how they are used. You are a different person with the gun in your hand' (Latour, 1999: 179) -or perhaps the keyboard?) The problem then lies with one perspective, that of ANT, which is centrally about what scientists do, but strays into the content of science, and another which is more concerned, at least initially, with the status of that content.

What this means is that the actor-network approach is much more immediately attractive to those in other areas, like IS, that are concerned with investigating concrete practice. Bhaskar's work itself is famously difficult and the issues are posed at a high level of abstraction. Archer sees herself as a sociologist attempting to build a working social theory, but even here the material is presented at a high level. The theory seems hard to apply to anything as mundane as an organisation, let alone an information system within one. By contrast, followers of ANT often tell a good story, and as a consequence ANT is seen as a good means of organising such tales about organisational life. Actornetwork theorists take mundane objects (such as the onions in a burger) and spin them into dense and complex tales. This, then, can seem attractive to those operating at an empirical level. However, one would want to express a note of caution here. To use Latour as an example, we have already noted that he falls foul of Sokal and Bricmont (1997). In truth, he comes off relatively lightly in that work, but stands accused of producing " 40 pages of comical misunderstandings of a theory that is nowadays routinely taught to intelligent college freshmen” in his piece on Einstein and relativity (Sokal, 1998). Closer to a more technological frame, his work on ARAMIS, a failed Parisian Metro system, tells us, in one reviewer's words: 
a great deal about Latour's fascination with Latour's ability to create chaos out of order and fog out of clarity. It tells us absolutely nothing about transport, technology, people, Paris, politics, society, economics, community, decision making and what might happen the next time round (Whitelegg, 1997).

The problem might be a confusion between good story telling and sound empirical work - although this might be regarded as the sour and humourless comment of an unrepentant modernist! However, more seriously it might represent the way in which actor-network perspectives fail to escape (and indeed, do not wish to escape) from the level of process. This is where there is a sharp difference from social realism.

What I take to be the distinguishing features of actor network theory are firstly, its insistence on the application of the term 'actor' to a wide range of humans and non-humans and secondly the mutual implication of these actors in the constructions of networks. We will look at the issue of actors below, but for now it follows that there is no distinction of micro and macro, or local and global or the many other dualisms that sociologists typically apply. As Sayer (1992) points out, it is extraordinarily difficult, if not impossible, to think about the world except in the form of paired opposites, such as 'people-nature' (and Lakoff and Johnson (1980) would indicate that such oppositions are built into the metaphors that we use, based in turn on our experiential construction of such metaphors). However, realists would argue for the efficacy and indeed necessity for a stance of analytical dualism, as discussed later (Reed, 1997). By contrast Law (1999) calls, rather excitedly, for a 'bonfire of the 
dualisms' and declares that the question of agency and structure is of no interest. Rather, the task for social analysts is simply to explore networks, providing rich descriptions of their development and operation. Latour, in arguing that “The Leviathan is a Skein of Networks.” asserts that

"However, if we wander about inside IBM, if we follow the chains of command of the Red Army, if we inquire in the corridors of the Ministry of Education, if we study the process of selling and buying a bar of soap, we never leave the local level.” (Latour, 1993: 121)

The notion of the task of social analysis being to delve below this local flux to determine, suggest, analyse more persistent patternings is rejected out of hand. In this sense, Whitley's complaint that

The possibility that these laboratories may be unusual in their pattern of working, or historically variable in their organization, does not seem to have been taken seriously by these authors who make no attempt to situate their studies in the broader social context.” (Whitley, 1984: 5)

would be rejected as immaterial. For Latour, society is the outcome of these networks, rather than the condition for their existence. By contrast, for Archer the status of human agency and the structures that it both produces and operates within are the prime questions for social analysts. This insistence rests in turn on a particular conception of human agency which actor-network theorists reject.

ANT calls upon us to adopt a symmetrical approach to humans and non-humans. John Law argues, “To insist on symmetry is to assert that everything deserves explanation and, more particularly, that 
everything that you seek to explain or describe should be approached in the same way” (1994: 9). In this, the way in which particular artefacts operate is deserving of as much attention as the behaviour of human actors. In some senses this might be seen as a useful attempt to redress the balance, much as attempts to consider the interests of, say, animals (Singer, 1998), are a valuable corrective to approaches which have insisted on a strict separation of Nature and Culture. (Indeed, such attempts should remind us, and actor-network theorists, that they are not the only ones to reject such dualisms). However, this seems to be a strange symmetry in which the powers of human beings are relatively neglected. Indeed, Archer argues, “The human being and the social agent are not identical. One sign of an adequate social theory is that it performs the introduction between them punctiliously: defective theories settle for reduction of one to the other (Archer, 1990: 97). However, for adherents of ANT, revealing their post-structuralist commitments, the human being is a purely social creation. As such, it becomes almost an epiphenomenon, the creation now not of deep structural factors but rather of complex networks. For Law, "agency is a product or an effect. Thus, since agents are not given by nature, we should be investigating how they got to be the way they are” (Law, 1994:11). For Archer, this would be to ignore the stratified nature of human society, in which human beings emerge from, but are not reducible to, physical materiality. From human beings emerge social actors who operate in a terrain conditioned by emerging structures - but human beings are not to be reduced to either. These notions of levels of reality and emergent powers are in complete opposition to the patterns proposed by ANT. It is the agent as social actor that is the matter of discussion here, and as such it can be equated to the world of things. Thus Latour (1987), in discussing the way in which people can speak for either things or other humans, assimilates both in arguing that they have no voice of their own. But whilst the things are blocked from speaking by their lack of both a voice and intentionality, and hence must have 
a representative, the humans are prevented from speaking by other causes - they cannot, for example, all speak at once. However, they are still capable of speech and hence the subversion of their representative. It is this difference in the ontological status of things and humans that lies at the heart of the rift between social realists and actor network theorists, not debates about the nature of the real.

For Latour has argued, as we have seen above, that the real is indeed a part of the world. In We Have Never Been Modern (1993: 6) he argues that, "Is it our fault if the networks are simultaneously real, like nature, narrated, like discourse, and collective, like society? " What Latour then proceeds to do is to take three thinkers as exemplars of these three constituent parts, as if this exhausted the range of possibilities. His thinkers are, for Nature E. O. Wilson, for society, Pierre Bourdieu and for discourse, Jacques Derrida. One asks, why these three? One can see, certainly, the choice of Derrida as being somewhat emblematic for those who see nothing beyond language, and we can turn to this issue in a moment. However, what is particularly interesting is the choice of a sociobiologist as the representative of nature. This is to ignore the huge debate on the relationship between the embodied nature of human beings and their powers of thought, a debate expressed in the works of, to name but a few, Dennett (1993), Edelman (1992), Searle (1997) and Rose (1997). Whilst there might be fierce debate between these, what they represent is a grappling with the embodied nature of human agency which at once places restrictions on what can be achieved and at the same time represents vast capacity for feelings and emotions far beyond the narrow constraints of artificial intelligence. Archer's discussion of the distinction between persons, agents and actors shows how such work can be brought into social theory without a reduction to psychology or beyond. This distinction is examined in more detail below, but it is interesting at this point to note how we can bring in Bourdieu and his work on 
the social shaping of patterns of thought and their embodiment through his notion of habitus. We can only do this with an ontology of depth that sees reality as stratified and emergent, a point that we return to shortly.

Let us finish this discussion of the problems with ANT, however, with one further issue which has already been alluded to, that is the issue of language, text and discourse. For many in ANT it has been seen as holding to the central tenets of the 'linguistic turn', in which language is no longer the transparent means of discourse but is the profound shaper of reality. Here, for example, are Bloomfield and Vurdubakis:

all forms of administrative, political and managerial intervention are not reactions to reality 'as such' but to a reality socially and discursively constructed within documents. What one might call a 'textual reality' (Bloomfield and Vurdubakis, 1997: 87).

A statement like this would seem to gather a good deal of support from Latour. After all, Science in Action begins with an elaborate dissection of the text, looking at the ways in which references, for example, are used as rhetorical devices. This was supported by an interest in citation analysis, which led some critics to argue that this was to over-rate the power of inscriptions. However, in more recent work there is a retreat from the pure power of the word. As he argues: 
"When we are dealing with science and technology it is hard to imagine for long that we are a text that is writing itself, a discourse that is speaking all by itself, a play of signifiers without signified.” (Latour, 1993: 64)

Whilst language and the text are vitally important parts of social analysis, they do not exhaust it, nor should analysis be reduced to it. Again, one would want to bring in the comments of feminist scholars to reinforce the centrality of the body. Hilary Rose (1994: 219) comments that "because body politics remains at the centre of feminist political struggle, the body serves to limit the capacity of words/texts to run off with everything." Once again, this points not only to the importance of the body in anchoring social analysis, but also to the need to recognise persistent patterning. One clear such patterning is gender inequality, which is an area of human existence little explored by the science studies from which ANT has emerged (Rose, 1994: 210; but see Fuller, 1993). However, the existence of such powerful patterns suggests something which goes beyond skeins of networks. The latter may well serve as a good device for telling stories, but not as an adequate means of social analysis.

Let me try to summarise this discussion so far. There are a number of tensions between a realist account and those presented by actor-network theorists. We have seen that the status of the 'real' (which is clearly crucial) is open to some debate even within actor-network theorists. As far as Nature is concerned, we have Latour's grudging realism, which means that we can leave this to debates within science studies. We also can put the language issue to one side and agree that language, discourse and texts are all vital to but not exhaustive of, social activity. We are then left with two central issues: of the nature of persons (and their relations with things) and the relationship of persons with society (for 
want of a better word to describe persistent patternings of human activity). I have argued above that ANT has a flat view of human agents, reducing them to effects and denying the embodied, emotional nature of human existence. This existence is still flatter, however, when it comes to social relations. For Latour "no one lives in a 'culture', shares a 'paradigm' or belongs to a 'society' before he or she clashes with others (1987:201). Once again, we live in a flat, endless present in which social action is all there is. To be sure, we might want to have a (fairly fruitless) argument about which came first, but surely we must recognise that people are both social actors and individuals at the same time and that the task for social analysis is to examine the contradictions, tensions and relationships between the two categories? Such, I take it, is the position that Archer adopts. This seems to me an altogether more successful tool for social analysis and in the next section I summarise its key features before looking at whether some of the detail of ANT, having rejected its broader claims, can be usefully employed in the context of social realism.

\section{Social realism}

Like Latour, Archer employs the notion of cycles of social interaction. However, unlike Latour, she is concerned to specify the phases of these cycles of action and, in particular, whether they are likely to lead to change or stasis. However, we also have to see these cycles of action in the context of an ontology of depth. This argues for the existence of stratified reality, in which a level emerges from, but is not reducible to, a prior level. In the case of persons, this might be to argue that memory, for example, is dependent on particular combinations of material reality which coexist in the brain. However, memory has emergent properties which exist at the level of the brain as a system and cannot 
be reduced to, for example, particular collections of connected material. In the same way, human beings are dependent on their bodies but their emotions, feelings and ways of activities cannot be reduced to them. In turn, those humans engage in social activity which produces structures and cultures which have emergent properties of their own. Such properties are sustained by and reproduced by human activity, but that human activity is not just that of 'these actors here present'. Rather, we must introduce the temporal dimension into analysis. This can be represented in the following diagram:

$\mathrm{T}^{2}$ Social interaction $\quad \mathrm{T}^{3}$

Structural elaboration $\mathrm{T}^{4}$

Figure 1: the morphogenetic cycle, (Archer,

1995)

This represents Archers 'morphogenetic' cycle (morpho indicating change, genetic emphasising the agential nature of change). Archer argues that in examining any discrete piece of social interaction, our analysis must start not at $\mathrm{T}^{2}$, that is, when the social interaction takes place, but rather at $\mathrm{T}^{1}$, that is, when the structural conditioning was formed, itself as the result of human activities. This structural 
conditioning might take the place of more or less material structures, such as institutions, organisations or markets, or of sets of ideas. When the start point is to be placed is a matter of choice and debate, but the essential point is that these factors act regardless of the participants' awareness. Social actors might be blissfully unaware of the conditions under which they are acting, but this does not dismiss the effects of those conditions. It is the task of social analysts, argues Archer, to construct analytic narratives that are avowedly provisional and debatable. However, what they seek to do is discern the cultural and structural conditions under which social action takes place, to examine the relationships between those conditions and the action which takes place and to consider the elaborations which then take place. In the context of the present discussion, these structural elaborations might take the form of particular information systems, systems which then form part of the structural conditioning in the next running of the cycle. Such systems are not then dependent for their existence on the social interaction that takes place. To be sure, they can be reproduced or ignored, but their existence is the product of previous interactions and it constrains or enables particular courses of action. In Archer's words

It is affirmed that social structures are only efficacious through the activities of human beings, but in the only acceptable manner, by allowing that these are the effects of past action, often by long dead people, which survive them (and this temporal escape is precisely what makes them sui generis (Archer, 1995: 148)

Central to this form of analysis is analytical dualism. If we are to examine the inter-relationships between structural conditioning and social interaction on the one hand, and the patterns of structural elaboration that emerge, it is vital that we hold the categories of agency and structure apart, for the purpose of analysis. As Sayer expresses it, 'Although social phenomena cannot exist independently of actors or subjects, they usually do exist independently of the particular individual who is studying 
them' (Sayer, 1992: 49) This seems to give better tools for analysis than the rather free floating, if undeniably interesting, stories which ANT produces. However, as I argued at the beginning of this paper, the place of technology in both social interactions and in structural conditioning is an invisible one at present. Can we use some of the insights of ANT to render technology a little more visible?

We might look at this in terms of the dimensions which Archer suggests. To start with the dimension of social interaction, we might want to start with the issue of what constitutes a social actor. The phrase 'social actor' is used deliberately, for Archer would argue that much social analysis has operated with an over-social view of the actor. That is, it concentrates its analysis on moments of social interaction, seeing actors as formed in that process. Archer argues that we need a perspective which has depth to it, in that it recognises the properties which individuals possess, as a consequence of their embodied nature. This in turn is mediated through various inter-related categories of agency, whereby persons (Archer's term for individual humans) belong to collective groups (agents), some based on factors which are determined, such as age and gender, some which possess degrees of freedom, such as voluntary associations. From this process of shaping emerge social actors. In the case of the use of information, we can see this as being able to take into account the cognitive limitations of individuals in contrast to accounts that stress the social production of knowledge as overcoming such limitations (Fuller, 1993) The problem with such accounts, and with those that just stop at the level of cognitive limitations, is that they ignore the social constraints on knowledge that actors possess by virtue of their membership of the social collectivities or agents to which they belong. It is here that we might want to bring in Bourdieu's (e.g. 1986) notion of habitus. This sense that patterns of thought are unconsciously acquired and embodied in differential fashion depending on, for example, the 
relation of agents to the division of labour, can direct our attention towards the links between social actors and their backgrounds (Mutch, 2000) ${ }^{1}$. Now, such a perspective shares in name only the characteristics of Latour's actors. For at the centre of Latour's analysis is the existence of classes of non-human actors, classes which Archer does not recognise in her analysis. Latour's urging is that we take seriously and treat symmetrically all those actors, human and non-human, who participate in particular social interactions. Such a prescription has been criticised by, for example, Collins and Yearley (1992), on the grounds that it fails to distinguish between human actors and others, and the term 'actant' is sometimes used. In terms of Archer's analysis, I would want to draw two distinctions.

One is that it can indeed be useful to conceive of non-humans as 'actants' in particular situations, if only to see them as important parts of social analysis (Walsham, 1997). However, treating non-humans symmetrically in methodological terms is not the same as conceding their ontological symmetry. For, as Fuller points out, the consequence of paying so much attention to non-humans is "diminishing the value of being a person” (1993: 342)). This comes not just from the greater attention that is paid to non-humans, but also from the conception of the human that non-humans are compared with. For, whilst we might take 'non-human' to be a broad category which includes, for example, animals and plants, in practice the focus is on machines. In particular, these machines have a 'reasoning' component and are often implicated in the debate over artificial intelligence. It will be argued below that this focus often exaggerates the powers of such technologies, but it also tends to reduce human beings to the status of centres of calculation. In Latour we find homo economicus reborn, the human as an effect of broader structures who can at best calculate the courses of actions open. This rather flat conception of the human has a cold, unemotional dimension to it (Laurier and Philo, 1999). For all 
Latour's delving into science studies (or perhaps because of it) and for all the hostility towards dualism, the overcoming of the mind/body dualism by much of contemporary thinking on the philosophy of mind seems to have passed him by (Fuller, 1993). This thinking, to summarise it very briefly, points to the centrality of the embodied mind, rather than the disembodied Cartesian mind, and to the vital role that emotions play in human activity. As Archer points out, what is excluded from images emanating from AI and, one would suggest, from Latour, "are human abilities for exercising wisdom, judgement, empathy, sympathy, discernment, responsibility, accountability and self-sacrifice” (1990: 109). The conclusion is, then, that one would want to consider the inter-relationships between humans and non-humans in social interaction, but that would want to examine empirically the strength of these relationships. We would also want to do so from a clear picture of what it is that characterises humans and non-humans. Such a characterisation would recognise that to talk of microbes or cows as having 'interests' and humans having interests is to be talking of two distinctive categories (Amsterdamska, 1990; Scott, 1992). Making such a distinction also entails, as Shapin (1998) points out, distinguishing between interests and the representation of those interests. Such a recognition allows us to bring explanation, rather than just description into the process of analysis. (For a defence of the notion of interests, see Callinicos, 1987)).

We might, then, want to amend approaches based on social realism to take account of the role of non-humans in the process of social interaction. How might this impact on structural conditioning and elaboration? A crucial notion for Latour is the durability of networks. Machines play a central role in this, involving the construction of 'black boxes' which conceal the social nature of their construction. Of particular value here are the notions of inscription and irreversibility. The construction of networks 
that are durable involves the inscription into material form of the assumptions that underpin the interests of particular actors in the network. In many organisations, for example, particular ways of working (notably within functional boundaries) are inscribed into software, inscriptions which subsequently make other forms of action difficult. The degree of difficulty depends on the irreversibility of such inscriptions, of unravelling the enrolments that happened to construct such inscriptions. This emphasis on the properties of technology seems to fit well with the realist emphasis on emergent properties. On such an account, such properties aren’t necessarily realised in practice. The exercise of their powers depends on the degree to which they can be realised in particular contexts, contexts which can be empirically examined. This is to argue, contra Grint and Woolgar (1997), that technology can be seen as having properties, but properties that partly emerge from the material characteristics of the technology and partly from the social processes that have shaped them. Such properties can be ignored by social actors, (as they have free will), but they are real constraints on the action in which they can engage. In particular, they can inscribe structural elaboration into relatively fixed properties that then form the social conditioning of the next round of social interaction. Technology is not infinitely malleable and there are limitations on interpretive freedom. However, to argue that technology possesses emergent properties is not to accord it independent power.

For ANT, to such machines are 'delegated' roles, such as decision-making. For Bloomfield, this is a crucial part of the cementing of particular structures. Delegation "refers to the ceding to technological artifacts or machines of social choices or values, of inclusions and exclusions, of rules and regulations, of wishes and intentions” (1995: 495). This is clearly an important way in which structures could be elaborated in such a way that that shape future social interaction. The most powerful influence of such 
shaping would occur when the participants indeed regard the technology as a 'black box', simply accepting its role as being that of neutral support. However, whilst one might want to test this empirically, one suspects that not all participants take such naive views. For one thing, this presupposes that the technology works, or works in the way in which it was intended. For another, we might want to question the nature of this delegation. Bloomfield uses the example of IT systems which recorded details of mental health patients and triggered warnings. In Bloomfield's terms:

"In other words, the systems [IT monitoring of mental health patients] are to be more than passive record keepers dedicated to the electronic storage of information: they are to be given the specific task of warning clinicians about particular patients without any prompting from the clinicians themselves. Thus the delegation here carries the urgency of a 'life and death' issue; such responsibilities are the most important delegations we can make to machines” (Bloomfield, 1995: 508-9).

But we face two problems in assessing this. To be sure, we have delegated a 'responsibility' to the machine, but is the nature of this responsibility such that it can be called 'life and death'? Surely that falls to whatever action the clinicians take upon it? The second is that we are left with this as a bald assertion. Did the clinicians in fact use it this way? Did the system work effectively, was it supplemented with other systems? What we get is the use of descriptive labels as a substitute for analysis (as we also find in, for example, the gross exaggeration of the role of steel rings in Dahlbom, Hanseth and Ljungberg's (2000) discussion of a 'material information system'). We have strayed here into issues of method, but let us first conclude that for those with a social realist approach, the power 
of technology to reinforce existing structural patternings is an important one. The language of ANT might be useful here, if shorn of some of its more extreme pretensions.

However, we would want to make one further caveat, and that is on grounds of methodology. Walsham (1997) wonders if ANT is used to shape inquiries, as well as to impose some analytical order on their findings. However, we might want to go further in criticising both approach and output. One suspects that, as Collins and Yearly argue, "some people are drawn to actant network theory because it provides a radical-looking descriptive terminology which, deep down, is undemandingly explanatorily conservative” (1992: 372). They go on further to criticise the extensive reliance on the analysis of texts. Texts are, indeed, central to ANT. For Bloomfield, “Networks cannot be observed directly, any more than the organization can, hence we must focus on their traces - for example, on the inscriptions which circulate within and between them” (1995: 495). However, whilst one might accept the importance of the analysis of a variety of inscriptions, such inscriptions often tell only one part of a story. What matters as much is how the inscriptions are constructed and used, supported or rejected. This demands an analysis which goes beyond semiotic analysis. It is, however, at such a level of analysis that ANT spends much of its time. Latour and other, for example, spend much time on 'sociotechnical analysis' (not to be confused with the socio-technical approach to system!) which produces indices and graphs (Scott, 1992). Such labours, which attempt to supply quantitative ways of analysing and comparing cases, mirror the concern with the individual as a centre of calculation, and the same caveats apply. This mode of operating seems to hark back to the positivist desire for calculative order and, in truth, to add little which might not be gained from a sensitive reading of the material. 


\section{Conclusion}

The gross and net result of it is that people who spend most of their natural lives riding iron bicycles over the rocky roadsteads of this parish get their personalities mixed up with the personalities of their bicycle as a result of the interchanging of the atoms of each of them and you would be surprised at the number of people in these parts who are nearly half people and half bicycles (O’Brien, 1974: 74).

Flann O’Brien's early adoption of actor-network theory might lead us to revise the old aphorism: history repeats itself, first as fiction, then as social theory. In truth, one suspects that the parallels between story telling and some modern social theory are strong. Of course, we might want to argue that it is in fiction that we can find the 'truer' account, (Rose, 1994) but we might also feel more comfortable if we know which was which. Walsham (1997) suggests that an engagement between structuration and ANT might be useful. In this paper, I have started the process of trying to translate and enrol parts of ANT into the realist project. I am sure that such an attempt would be resisted by those who support ANT! However, what I have tried to suggest are areas where a constructive engagement might be useful. This would indicate that some of the apparatus used to describe processes might indeed be of value. Of most importance might be the incorporation of non-humans into the analysis of social interaction and of technology into the elaboration of structures. However, such incorporation would be in the context of an adherence to the central concepts of an ontology of depth, which sees human actors as emerging from, but not reducible to, a material body. This in turn places limitations on the use of language which suggests that the focus of ANT on inscriptions is only 
partially useful. The most important challenge would seem to be to mount a resistance to what Callinicos (1999) outlines as a powerful anti-naturalist tendency in 20th century social thought, a tendency which hinders our attempts to trace the relationships between people and the structures they create without collapsing into a biological reductionism on the one hand or a privileging of structures (or non-humans!) on the other.

\footnotetext{
${ }^{1}$ The notion of habitus has found some use, if rather undeveloped, in accounts of the social nature of learning and knowledge creation in organisations (Lave and Wenger, 1991; Von Krogh, Ichijo and Nonaka, 2000) Such accounts, however, tend to treat the concept uncritically. This is not the place to expand on the criticisms that can be levelled, but they centre on the emphasis on reproduction, as opposed to change and the failure to account for changes that the reflexivity of late modernity might bring (See the discussion in Calhoun, LiPuma, and Postone, (1993)) However, it is interesting to note Fowler's (1997) locating of Bourdieu in the tradition of realism.
} 


\section{References}

Amsterdamska, O. (1990) ‘Surely You Are Joking, Monsieur Latour!’, Science, Technology \& Human Values 15(4): 495-504.

Archer, M. (1990) ‘Theory, Culture and Post-Industrial Society’, in Featherstone, M.

(ed.) Global Culture, London: Sage, 97-119.

Archer, M. (1995) Realist social theory: the morphogenetic approach. Cambridge:

Cambridge University Press.

Archer, M. (1996) Culture and agency. The place of culture in social theory.

Cambridge: Cambridge University Press.

Bloomfield, B. (1995) 'Power, Machines and Social Relations: Delegating to Information Technology in the National Health Service', Organization 2(3/4): 489518.

Bloomfield, B., and Vurdubakis, , T. (1997) 'Paper Traces: Inscribing Organizations and Information Technology’, in Bloomfield B., Coombs, R., Knights, D and Littler, D. (eds) Information Technology and Organizations, Oxford: Oxford University Press 85-111.

Bourdieu, P. (1986) Distinction: a social critique of the judgement of taste. London: Routledge.

Calhoun, C, LiPuma, E. and Postone, M. (1993), Bourdieu: Critical Perspectives, Cambridge: Polity

Callinicos, A. (1985) ‘Anthony Giddens, a Contemporary Critique’, Theory and Society, 13, pp. 133-166

Callinicos, A. (1987) Making History. Oxford: Polity. Callinicos, A. (1999) Social Theory: a Historical Introduction. Cambridge: Polity. 
Checkland, P. and Holwell, S. (1998) Information, Systems and Information Systems:

Making Sense of the Field. Chichester: Wiley.

Ciborra, C. and Associates (2000), From Control to Drift: The Dynamics of Corporate Information Infrastructures, Oxford: Oxford University Press.

Collier, A. (1994) Critical Realism: an Introduction to the Philosophy of Roy Bhaskar. London: Verso.

Collins, H. M.,and Yearley, S. (1992) ‘Journey into Space’, in Pickering, A.(ed), Science as Practice and Culture Chicago: Chicago University Press, 369-389.

Currie, W., and Galliers, , B. (1999) Rethinking Management Information Systems.

Oxford: Oxford University Press.

Dahlbom, B., Hanseth, O. and Ljungberg, J (2000) 'Conservative Success:

Organization and Infrastructure Evolution at SKF', in Ciborra, C. et al (eds.), From Control to Drift: The Dynamics of Corporate Information Infrastructures, Oxford: Oxford University Press, pp. 87-104.

Dennett, D. C. (1993) Consciousness Explained. Harmondsworth: Penguin.

DeSanctis , G. and Poole, M. (1994) 'Capturing the Complexity in Advanced Technology Use: Adaptive Structuration Theory’, Organization Science, 5(2), pp.121-147.

Edelman, G. M. (1992) Bright Air, Brilliant Fire. On the Matter of the Mind. Harmondsworth: Penguin.

Fowler, B (1997) Pierre Bourdieu and Cultural Theory: critical investigations, London: Sage.

Fuller, S. (1993) Philosophy, Rhetoric and the End of Knowledge: The Coming of Science and Technology Studies. Madison, WI: University of Wisconsin. 
Grint, K. and Woolgar, S. (1997) The Machine at Work: Technology, Work and Organization, Cambridge: Polity.

Jones, M. (1999) ‘Structuration Theory’, in Currie, W. and Galliers, R. (eds)

Rethinking MIS, Oxford University Press: Oxford 103-135.

Lakoff, G. and Johnson, M. (1980) Metaphors we live by, Chicago: University of Chicago.

Latour, B., and Woolgar, , S. (1979) Laboratory Life. The Social Construction of Scientific Facts. Beverly Hills: Sage.

Latour, B. (1987) Science in Action: how to follow scientists and engineers through society. Cambridge, MA: Harvard University Press.

Latour, B. (1993) We Have Never Been Modern. Hemel Hempstead: Harvester Wheatsheaf.

Latour, B. (1999) 'On recalling ANT', in Law, J. and Hassard, J. (eds) Actor Network Theory and After. Oxford: Blackwell 15-25.

Latour, B. (1999) Pandora's Hope: Essays on the Reality of Science Studies, Cambridge MA: Harvard University Press.

Laurier, E., and Philo, , G. (1999) 'X-morphising: review essay of Bruno Latour's Aramis, or the Love of Technology', Environment and Planning A 31: 1047-1071. Law, J. (1994) Organizing Modernity. Oxford: Blackwell.

Law, J., and Hassard, J. (1999) Actor Network Theory and After. Oxford: Blackwell. Law, J. (1999) ‘After ANT: complexity, naming and topology’, in Laws, J. and Hassard, J. (eds) Actor Network Theory and After. Oxford: Blackwell 1-14.

Lave, J and Wenger, E. (1991), Situated Learning: Legitimate Peripheral Participation, Cambridge: Cambridge University Press. 
Miller, P. (1997) ‘The Multiplying Machine’, Accounting, Organisations and Society 22(3/4): 355-364.

Monteiro, E. and Hanseth, O. (1996), 'Social Shaping of Information Infrastructure:

On Being Specific about the Technology’, in Orlikowski et al, (eds) Information Technology and Changes in Organizational Work, London: Chapman Hall, pp. 325343.

Mutch, A. (2000) 'Managers, information and teams: a tale of two companies', The New Review of Information Behaviour Research, 1, pp. 151-166

Norris, C. (1998) 'Review of Intellectual Impostures', The Independent at http://www.independent.co.uk/books/stories/BR001483.htm 18 July

O’Brien, F., (1974) The Third Policeman, London: Picador.

Orlikowski, W. (1992) 'The Duality of Technology: Rethinking the Concept of Technology in Organizations’, Organization Science, 3(3), pp. 398-427.

Outhwaite, W. (1987) New Philosophies of Social Science: Realism, Hermeneutics and Critical Theory. London: Macmillan.

Pickering, A. (1992) Science as Practice and Culture. Chicago: Chicago University Press.

Reed, M. (1997), In Praise of Duality and Dualism: Rethinking Agency and Structure in Organizational Analysis’, Organizational Studies, 18(1), pp. 21-42.

Roberts, R. H. and Good, J. M (1993) The recovery of rhetoric: persuasive discourse and disciplinarity in the human sciences. London: Bristol Classical Press.

Rose, H. (1993) 'Rhetoric, Feminism and Scientific Knowledge Or From Either/Or

To Both/And', in Roberts, R. and Good, J. (eds) The Recovery of Rhetoric. London: Bristol Classical Press. 203-223.

Rose, S. (1993) The Making of Memory. From molecules to mind. London: Bantam. 
Rose, H. (1994) Love, power and knowledge: towards a feminist transformation of the sciences. Cambridge: Polity.

Sayer, A (1992) Method in Social Science: A Realist Approach, London: Routledge.

Scott, J. K. (1992) ‘Exploring Socio-Technical Analysis: Monsieur Latour Is Not Joking!', Social Studies of Science 22: 59-80.

Searle, J. R. (1997) The Mystery of Consciousness. London: Granta.

Shapin, S. (1988) 'Following Scientists Around', Social Studies of Science 18: 53350.

Singer, P. (1998) ‘A vegetarian philosophy’, in Griffiths, S and Wallace, J, (eds.)

Consuming Passions: Food in the Age of Anxiety, Manchester: Mandolin, 71-79.

Sokal, A., and Bricmont, , J. (1998) Intellectual Impostures. Postmodern

philosophers'abuse of science. London: Profile.

Sokal, A. D. (1998) 'What the Social Text Affair Does and Does Not Prove', available at http://www.physics.nyu.edu/faculty/sokal/noretta.html

Von Krogh, G., Ichijo, K. and Nonaka, I. (2000) Enabling Knowledge Creation: How to Unlock the Mystery of Tacit Knowledge and Release the Power of Innovation,

Oxford: Oxford University Press.

Walsham, G (1993) Interpreting Information Systems in Organisations, Chicester: Wiley.

Walsham, G. (1997) ‘Actor-Network Theory and IS Research: Current Status and Future Prospects', in Lee, Liebenau and DeGross (eds) (1997), Information Systems and Qualitative Research 466-480.

Watson, T., and Harris, , P. (1999) The Emergent Manager. London: Sage.

Whitelegg, J. (1997) 'On a highway to hell’, Times Higher Education Supplement 7 March: 
Whitley, R. (1984) The Intellectual and Social Organization of the Sciences. Oxford:

Clarendon.

Wilde, O. (1986) The Importance of Being Earnest and Other Plays. Harmondsworth:

Penguin.

Willmott, R. (2000) 'The Place of Culture in Organization Theory: Introducing the Morphogenetic Approach', Organization, 7(1), pp. 95-128. 